\title{
Wind tunnel Assessment of Wind Environment and Dust Suppression Effect of Windbreak in Port Bulk Storage Yards
}

\author{
Ning $\mathrm{Su}^{1}$, Ningning Hong ${ }^{1 *}$, Shitao Peng ${ }^{1}$, Hongxin $\mathrm{Zhao}^{1}$ and Tao $\mathrm{Hu}^{1}$ \\ ${ }^{1}$ Tianjin Research Institute for Water Transport Engineering, Ministry of Transport of the People's Republic of China, Tianjin 300456, \\ China
}

\begin{abstract}
Windbreaks projects are constructed in order to reduce the dusting in port bulk storage yards. The assessment of wind environment and dust suppression effects are important in the planning or preliminary design of such projects. This paper takes a large port bulk storage yard with $853 \mathrm{~m} \times 966 \mathrm{~m}$ area as an example, velocity measurement wind tunnel tests were carried out. The wind velocity reduction ratio and dust suppression rate were used to access the wind environment and the dust suppression effect. The influence of windbreak height was investigated. The comprehensive wind speed reduction rate and dust suppression rate vary with windbreak height nearly linearly. And combined with spraying system, the dust suppression rate can reach beyond $95 \%$, which provides reference and assessment method for relative engineering applications.
\end{abstract}

\section{Introduction}

Dusting in port bulk storage yards is one of the key atmospheric pollution sources for coastal cities. And dusting form bulk piles contribute the most to the port dust pollution [1]. Windbreaks are porous plates that could reduce the wind speed and optimise the wind environment thus suppressing the dusting. Windbreak projects constructed in the bulk storage yards are effective dust suppression facilities, which have been widely applied in engineering practices. However, the selection of windbreak parameters was important especially in the preliminary design process, including the horizontal plan, height and prosperity of the windbreaks.

The assessment of the wind and dust suppression effect should also consider the meteorological conditions and pile conditions. Usually CFD simulation or wind tunnel test should be carried out to assess of the wind and dust suppression effect. CFD simulation on the wind environment takes less effort and fruitful results should be used in the preliminary plan $[2,3]$. While wind tunnel tests with higher precision, however takes much effort and resources, should be carried out to validate the parametric settings, and provide more evident data to support the detailed construction plans, which is crucial for large and important projects $[4,5]$. However, some detailed information of key assessment indexes for windbreak engineering application was rarely reported and discussed in literatures, which requires further investigation.

This paper takes a large port bulk storage yard with $853 \mathrm{~m} \times 966 \mathrm{~m}$ area as an example, wind tunnel tests were carried out. The wind velocity reduction ratio was sued to access the wind environment and dust suppression rate were to evaluate the dust suppression effect of the construction of windbreak project. The influence of windbreak height was investigated, which provide reference and assessment method for relative engineering applications.

\section{Wind tunnel test}

\subsection{Test devices and models}

The wind tunnel test was carried out in the open circuit wind tunnel with $2.5 \mathrm{~m} \times 4.4 \mathrm{~m}$ section wind tunnel at Tianjin research institute for water transport engineering (TIWTE). The wind tunnel was driven by a $440 \mathrm{~kW}$ DC motor with maximum simulation wind speed $30 \mathrm{~m} / \mathrm{s}$.

The research object was a large port bulk storage yard with $853 \mathrm{~m} \times 966 \mathrm{~m}$. The diameter of the yard is about $1.3 \mathrm{~km}$ with the geometric centre of the yard as the centre. According to the geometric scale ratio of 1:350, the ABS plate is used to make the wind tunnel test model of stacking, and the interference of buildings / structures inside the yard is considered (Fig. 1a). The windbreak was made of ABS with $30 \%$ prosperity (see Fig. b). Irwin probe speed measuring point is arranged on the front and side of each pile surface, 65 stacks are arranged in the yard, 5-6 probes are arranged in each stack (see Fig. 1d), 328 Irving probes are arranged in total, each Irwin probe measuring point has both static and total pressure measuring channels(see Fig. 1c), thus, 656 pressure measuring channels in total. 


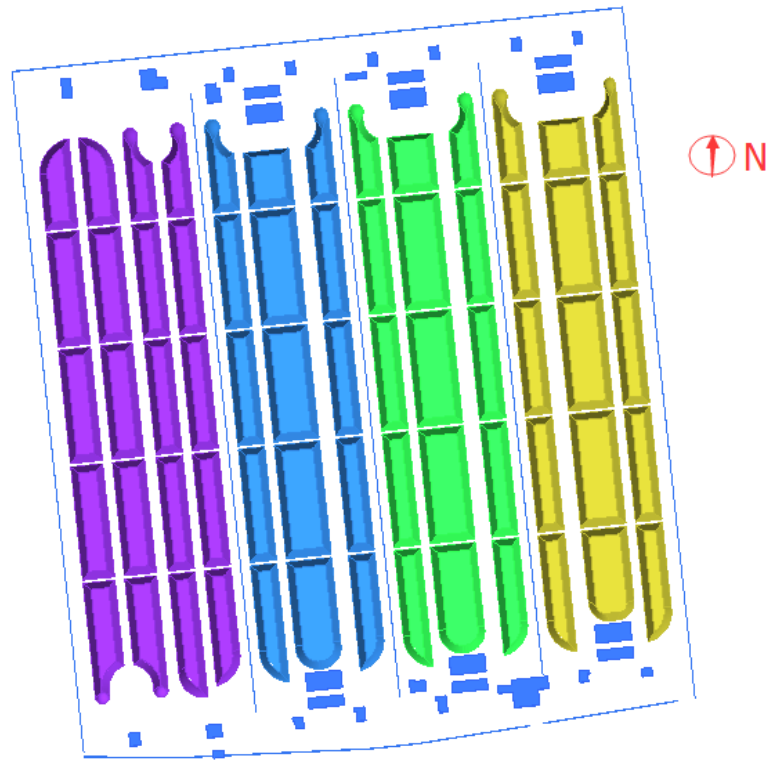

(a) port bulk storage yard
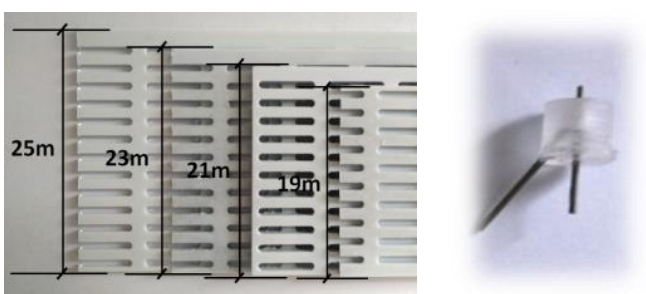

(b) windbreak model

(c) Irwin probes
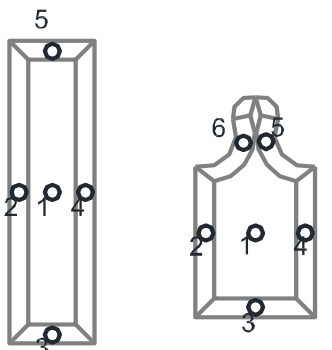

(d) measuring taps on piles

Figure 1. wind tunnel teste model.

\subsection{Test conditions and cases}

The atmospheric boundary layer (B type in GB50009-2012[6]) was simulated with power law index 0.15 by roughness elements arranged in the wind tunnel. The simulated wind profile was shown in Fig. 2.

In this wind tunnel test, the geometric scale ratio is $1: 350$, and the wind speed ratio is $1: 1$. According to dimensional analysis, the time scale ratio is $1: 350$, and the sampling time is $15 \mathrm{~s}$, which corresponds to the actual wind speed statistical time interval of more than 1 hour,

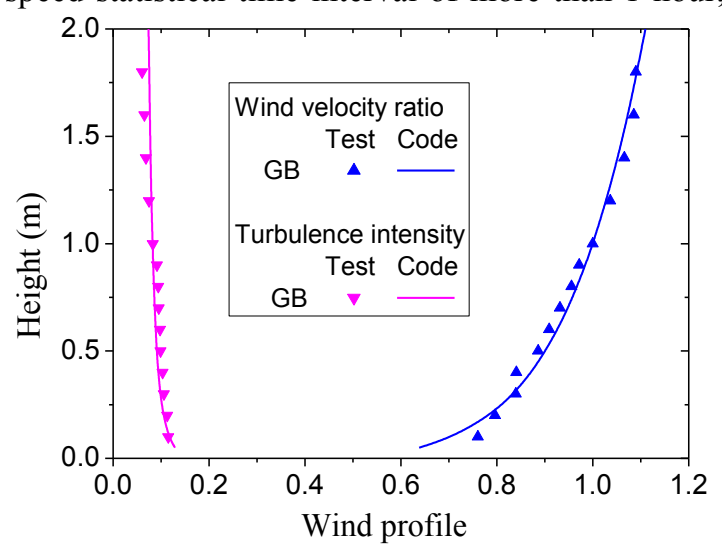

Figure 2. Simulated wind profile. meeting the measurement requirements. In this wind tunnel test, the wind speed of each stacking surface in 16 wind directions under three conditions of no windbreak, windbreak height of $19 \sim 25 \mathrm{~m}$ was measured by Irwin probe through electronic pressure scanning valve. During the test, Cobra Probe is used to measure the incoming reference wind speed at the stacking height of the incoming flow position. In each case, 16 azimuths were considered, $\mathrm{N}$ for $0^{\circ}$, tested in each $22.5^{\circ}$. The test cases were shown in Table 1 and the test photos of each condition were shown in Fig. 3.

Table 1. Details of test cases

\begin{tabular}{|c|c|}
\hline Case \# & Case description \\
\hline $1 \sim 16$ & no windbreak \\
\hline $17 \sim 32$ & windbreak height $19 \mathrm{~m}$ \\
\hline $33 \sim 48$ & windbreak height $21 \mathrm{~m}$ \\
\hline $49 \sim 64$ & windbreak height $23 \mathrm{~m}$ \\
\hline $65 \sim 80$ & windbreak height $25 \mathrm{~m}$ \\
\hline
\end{tabular}




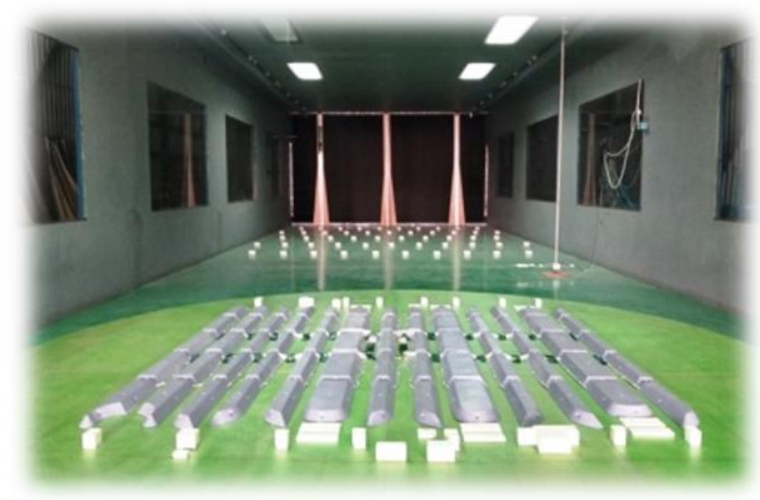

(a) no windbreak

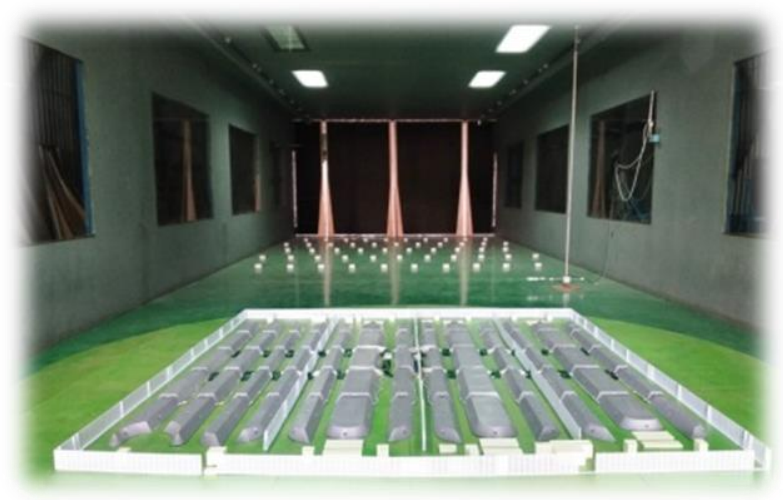

(b) with windbreak (height $25 \mathrm{~m}$ )

Figure 3. Test photo of each case.

\section{Result and discussion}

\subsection{Data processing methods}

\subsubsection{Wind velocity reduction ratio}

The wind velocities measured by the Irwin probe in each case was processed as non-dimensional wind velocity reduction ratio denoted as $\lambda_{j}$

$$
\lambda_{j}=U_{j 1} / U_{j 0}
$$

where $U_{j 0}$ is the wind velocity on measuring tap $j$ of pile surface without windbreak (from case $1 \sim 16$ ). And $U_{j 1}$ is the wind velocity on measuring tap $j$ of pile surface with windbreaks of different heights (from case 17 80). $\lambda_{j}$ denotes the influence of windbreaks on wind environment. The lower value of $\lambda_{j}$ means the more effective windbreak acts. To average the wind velocity reduction ratio with surface area, the bulk yard wind velocity reduction ratio was calculated as

$$
\lambda=\frac{\sum_{j} U_{j 1} A_{j}}{\sum_{j} U_{j 0} A_{j}}
$$

where $A_{j}$ is the surface area of each measuring tap $j$. Then $\lambda$ denotes the comprehensive wind environment situation under a certain windbreak plan.

\subsubsection{Dust suppression rate}

Using the dusting formula recommended by EPA[7], the dusting coefficient is related to the friction velocity, estimated by

$$
Q=\sum_{j} B_{j} k_{D j} w_{D j} P_{D j} A_{j}
$$

$$
P_{D j}=\left\{\begin{array}{cl}
58\left(u_{j}^{*}-u_{D j t}^{*}\right)^{2}+25\left(u_{j}^{*}-u_{D j t}^{*}\right) & u_{j}^{*}>u_{D j t}^{*} \\
0 & u_{j}^{*} \leq u_{D j t}^{*}
\end{array}\right.
$$

$$
u_{j}^{*}=\frac{u_{j z} \kappa}{\ln \left(z / z_{0}\right)}, \quad z>z_{0}
$$

where $Q$ is the dusting coefficient, $B_{j}$ is the material dusting modification coefficient of tap $j, k_{D j}$ is the dusting factor of $\operatorname{tap} j, w_{D j}$ is the material mass factor of tap $j, P_{D j}$ is the dusting potential of $\operatorname{tap} j, u_{j}$ is the friction velocity of $\operatorname{tap} j, u^{*}{ }_{D j t}$ is the critical friction velocity of $\operatorname{tap} j, u_{z j}$ is the wind velocity of at height $z$ of tap $j, z_{0}$ is the roughness length and $\kappa$ is the von-Karman constant. The comprehensive dust suppression rate $\eta$ was calculated by

$$
\begin{gathered}
E_{i}=Q_{i 1} / Q_{i 0} \\
\eta=\left(1-\sum_{i} E_{i} \cdot f_{i}\right) \times 100 \%
\end{gathered}
$$

where $Q_{i 0}$ is the dusting coefficient of the $i$ th azimuth without windbreak (from case $1 \sim 16$ ). And $Q_{i 1}$ is the dusting coefficient of the $i$ th azimuth with windbreak of different heights (from case 17 80). $E_{i}$ is the dusting rate of the $i$ th azimuth and $f_{i}$ is the wind frequency of azimuth $i$ obtained form meteorological information.

\subsection{Wind environment assessment}

The bulk yard wind velocity reduction ratio calculated by Eq. (2) was plotted in a rose map shown in Fig. 4. It is indicated from the figure that, as the windbreak height increase, the wind velocity is reduced. When the flow are direct to the windbreak plates $(\mathrm{N}, \mathrm{E}, \mathrm{S}, \mathrm{W})$ the wind velocity reduced more than the oblique flows.

The dusting rate showed opposite feature, demonstrated by Fig.5. Under the flow are direct to the windbreak plates $(\mathrm{N}, \mathrm{E}, \mathrm{S}, \mathrm{W})$, the dusting is effectively suppressed. For the flow from the corner of the bulk yard, dusting still remained to some extent. 


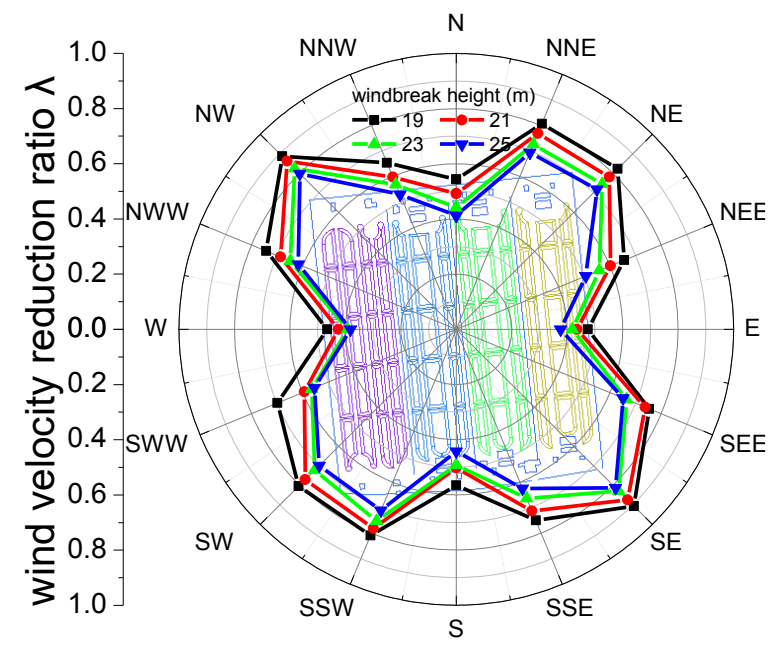

Figure 4. Wind velocity reduction ratio

\subsection{Dust suppression effect}

The wind velocity reduction ratio and dust suppression rate are plotted with non-dimensional height (the ratio between windbreak height and pile height), shown in Fig. 6 . It can be inferred that in the non-dimensional height

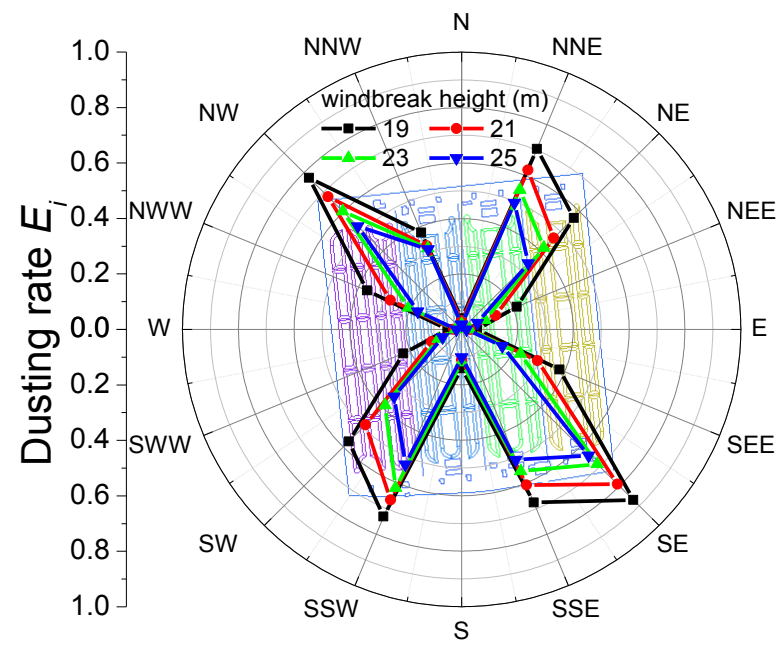

Figure 5. Rose map of dusting rate

range 1.25 to 1.7 , the variation of wind velocity reduction ratio and dust suppression rate with non-dimensional height is nearly linear. It can be also inferred from figure that, combined with spraying system, when the moisture content reach about $8.0 \%$, the dust suppression rate could reach more than $95 \%$.

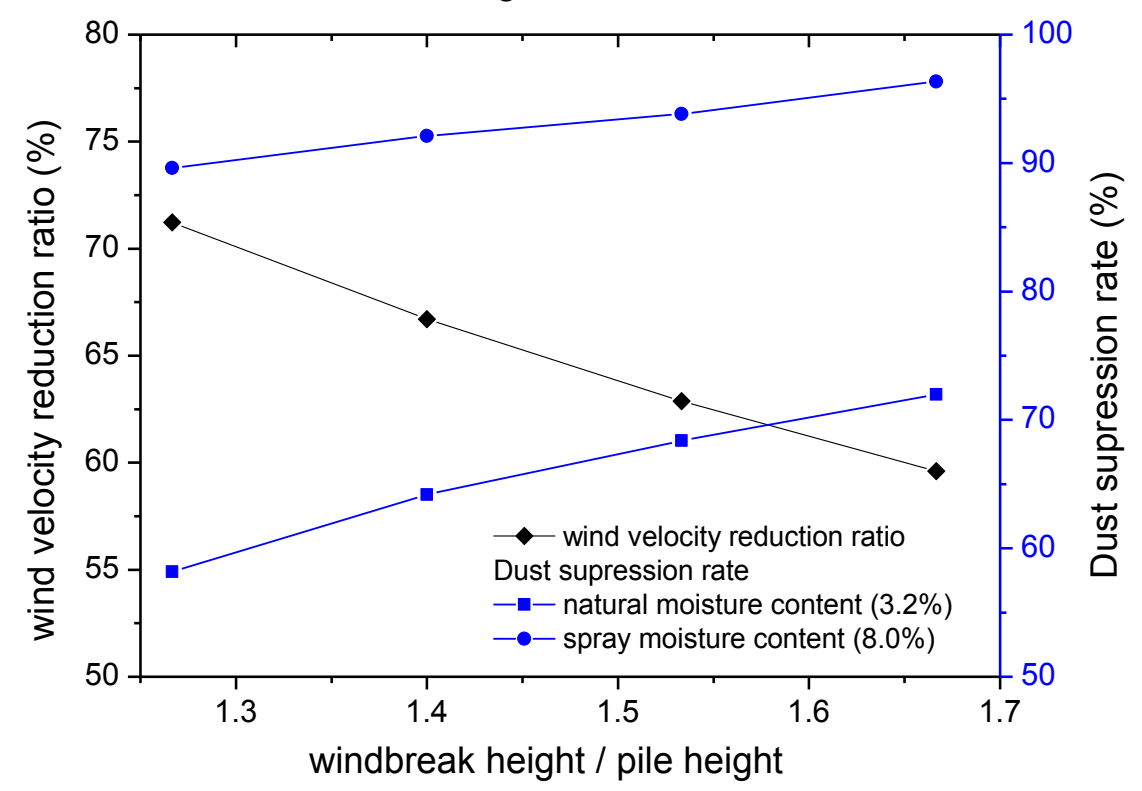

Figure 6. Wind velocity reduction ratio and dust suppression rate with non-dimensional height

\section{Conclusion}

In this paper, wind tunnel tests on accessing the wind environment and dust suppression effect of a large port bulk storage yard with $853 \mathrm{~m}$ x $966 \mathrm{~m}$ area were carried out. The wind velocity reduction ratio to access the wind environment and dust suppression rate were to evaluate the dust suppression effect of the construction of windbreak project. The results shows that the windbreak shows better effect when the flow comes direct to the plates than oblique flows. The comprehensive wind speed reduction rate and dust suppression rate vary with windbreak height nearly linearly, which provides reference and assessment method for relative engineering applications.

\section{Acknowledgments}

This research has been supported by the China National Key R\&D Program (Grant No. 2016YFE0204800), Tianjin Transportation Science and Technology Development Project (Grant Nos. 2018-b4, 2019-11) and the Fundamental Research Funds for the Central Public Welfare Research Institutes (Grant No. TKS190204). 


\section{References}

1 Qingxin Lu, Ningning Hong, Shuifen Zhan, Shitao Peng, Xin Li \& Hang Yu. (2008). Research progress on prevention and control technologies of dust pollution in ports. Journal of Waterway and Harbor, (6), 451-452.

2 J. D. Wilson. (1987). On the choice of a windbreak porosity profile. Boundary-Layer Meteorology, 38(1), 37-49.

3 Edward G. Patton, Roger H. Shaw, Murray J. Judd, \& Michael R. Raupach. (1998). Large-eddy simulation of windbreak flow. Boundary-Layer Meteorology, 87(2), 275-307.

4 Yaqing Zhang, Guangyu Zhang, Shuifen Zhan \& Mingxin Dai. (2007). Numerical simulation of windbreak net's dustproof effect in coal container yard. Journal of Waterway and Harbor 28(2), 136-139.

5 Guangyu Zhang, Mingshui Li, Shuifen Zhan \& Qi Tao. (2008). Wind tunnel investigation on porous fence of a large coal-pile yard. Journal of Experiments in Fluid Mechanics, 22(4), 58-62.

6 GB50009 (2012) Load code for the design of building structures. Beijing, China.

7 US EPA (1988) Update of fugitive dust emissions factors. In: AP-42 Section 11.2 wind erosion, MRI No. 8985-K. Midwest Research Institute, Kansas City, MO. 